\title{
Efficient Archery Posture Training Analysis of Archery Performances for the Talent Development and Excellence Achievements
}

\author{
Chaturong Hemara ${ }^{1}$, Pravet Ketkan ${ }^{2, *}$, Juthamas Singchainara ${ }^{3}$, Toansakul Tony Santiboon ${ }^{4}$ \\ ${ }^{1}$ Thailand National Sports University, Lampang Campus, Lampang, Thailand \\ ${ }^{2}$ Thailand National Sports University, Mahasarakam Campus, Mahasarakam, Thailand \\ ${ }^{3}$ Faculty of Education, Kasetsart University, Bangkok, Thailand \\ ${ }^{4}$ Curtin University of Technology, Bentley Campus, Perth, WA, Australia
}

Received April 8, 2021; Revised November 12, 2021; Accepted November 22, 2021

\section{Cite This Paper in the following Citation Styles}

(a): [1] Chaturong Hemara, Pravet Ketkan, Juthamas Singchainara, Toansakul Tony Santiboon , "Efficient Archery Posture Training Analysis of Archery Performances for the Talent Development and Excellence Achievements," International Journal of Human Movement and Sports Sciences, Vol. 9, No. 6, pp. 1435 - 1446, 2021. DOI: 10.13189/saj.2021.090640.

(b): Chaturong Hemara, Pravet Ketkan, Juthamas Singchainara, Toansakul Tony Santiboon (2021). Efficient Archery Posture Training Analysis of Archery Performances for the Talent Development and Excellence Achievements. International Journal of Human Movement and Sports Sciences, 9(6), 1435 - 1446. DOI: 10.13189/saj.2021.090640.

Copyright $₫ 2021$ by authors, all rights reserved. Authors agree that this article remains permanently open access under the terms of the Creative Commons Attribution License 4.0 International License

\begin{abstract}
The design of effective archery skills of archers for the excellence of international games was analyzed. The time taken for each shot between an arrow scored 10 points, and compared an arrow scored under 10 points with a sample size of 31 archers with international competitions' experiences for 6 times on Actual Form (scoring of 79\% before their participation) and Preferred Form (scoring of $86 \%$ after they trained and practiced) Skills for the Archer Performance Skill (APA) Form, differently. The adaptation of the Archery Skill Analysis Assessment Form (ASAAF) was assessed. Assessing associations between the archery skill and the abilities of archers in their actual and preferred forms, their efficient archery posture training with archery performances for the excellence achievements is related to two variables, relatively. The efficient predictive $\mathrm{R}^{2}$ values indicate that $51 \%$ and $69 \%$ of the variances in archery abilities are related to their archery performance skills' achievements. Analysis of archery skills comprises 10 skills, such as, stability, hooking, drawing, anchoring, loading/transfer to hold, physical strength and stability, developing intense focus and concentration, aiming, releasing, and following through skills that are trained and practiced by professional archery expert. The study is very important, which is one of only a handful of studies in archery sport in Thailand,
\end{abstract}

and represents one of the only studies worldwide that has focused on archery sport to improve the analysis of efficient archery posture training for excellence achievements. It may solve problems that have been accumulated for a long time.

Keywords Volunteer Archery, Efficient Archery Posture, Training and Practice, Analysis of Archery Performances and Excellence Achievements, Associations and Comparisons

\section{Introduction}

Normally, archery is the art, sport, practice, or skill of using a bow to shoot arrows [1]. The word comes from the Latin arcus for bow (Paterson, 1985: p. 11)[1]. Historically, archery has been used for hunting and combat. In modern times, it is mainly a competitive sport and recreational activity. A person who participates in archery is typically called an archer or a bowman, and a person who is fond of an expert in archery is sometimes called a toxophilite or a marksman (Lombard, 2020)[2]. Interestingly, archery was highly developed in Asia. The 
Sanskrit term for archery, dhanurveda, was used to refer to martial arts (Backwell et al., 2008)[3]. In East Asia, Goguryeo, one of the Three Kingdoms of Korea, was well known for its regiments of exceptionally skilled archers (Duvernay and Duvernay, 2007)[4]. Classical civilizations, notably Assyrians, Greeks, Armenians, Persians, Parthians, Romans, Indians, Koreans, Chinese, and Japanese, fielded large numbers of archers in their armies (Zutterman, 2003)[5].

The development of firearms made bows obsolete in warfare (Gunn, 2010) [6]. Armies equipped with guns could thus provide superior firepower and highly trained archers (Spacewar.com (2012) [7]. Bow and arrow is still an effective weapon, and archers have seen action in the 21st century (Okeowo, 2012)[8]. Modern game archery is largely due to Fred Bear, an American bow hunter and bow manufacturer (Bertalan, 2007) [9]. We now consider archery an internationally standard sport as it includes, at the Olympic Games level, Asian Games, and SEA Games by organizing competitions in categories Recurve bows and compound bows classified into male and female types (World Archery, 1994)[10].

\subsection{Types of Bows}

Some may broadly split bows into two categories: those drawn by pulling the string directly and those that use a mechanism to pull the string. Recurve bows and some types of longbows have tips that curve away from the archer when the bow is unstrung (Figure Caption 1(a)).

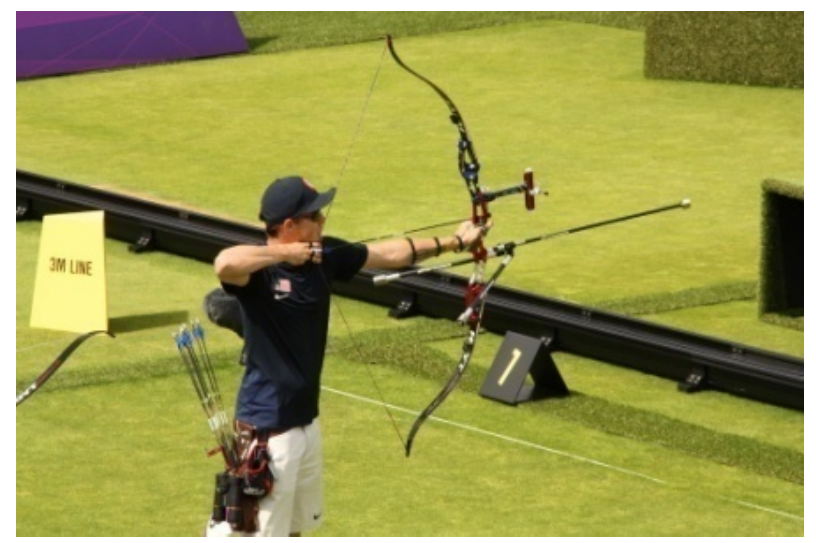

a) A Recurve Bows

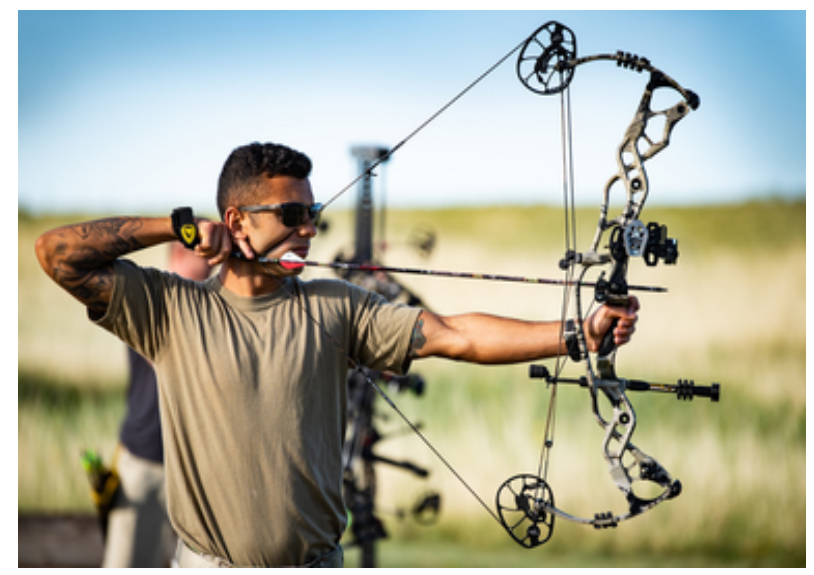

b) Compound Bows

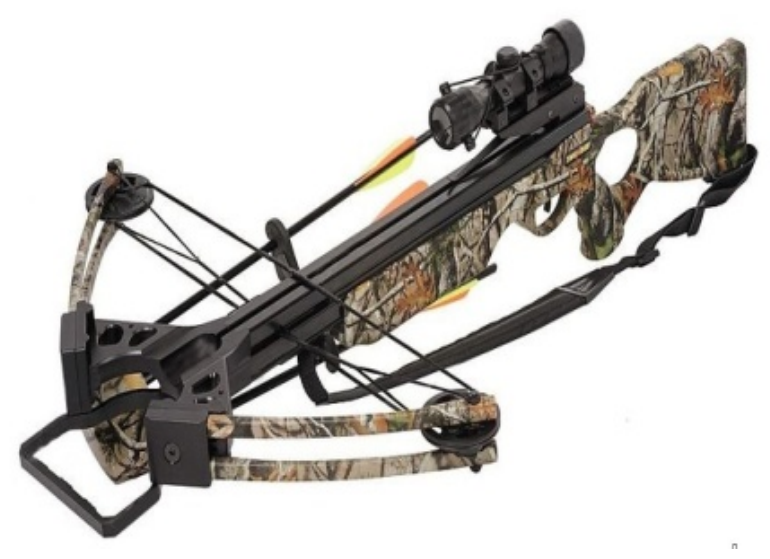

c) A Crossbow

Source: a) Huntracths.com (2018)[11]; b) Archery Bow Club (2020)[12]; c) Archery Dude (2018)[13]

Figure 1. Types of Bows

The classic longbow is a tall bow with narrow limbs that are D-shaped in the cross section, and the flat bow has flat wide limbs that are approximately rectangular in the cross section (Seokgyu-Choi and Jeong, 2010)[14]. However, they have technology similar to that of other bows and work in the same way. Therefore, crossbows are part and parcel of archery and should be fully accepted in the sport (Sontrop, 2021) [15] best type of bow for a beginner is a recurve bow. This will allow archers to learn the basics of archery with the most versatile and cost-effective type of bow before archers consider getting a more expensive compound (James, 2021)[16]. 


\subsection{Types of Arrows and Fletching}

Focused on the archery sport, an archer shoots either 3 arrows per end (indoors) or 6 arrows per end (outdoors). After each end, the competitors walk to the target to score and retrieve their arrows (Brockington, 2004)[17]. Fletching on an arrow shaft stabilizes the shaft during flight by causing it to spin as it leaves the bow, just as a quarterback puts a spiral spin on the football as he passes. Spinning keeps the arrow on its flight path and preserves speed, accuracy, and, ultimately, impact power (Bowhunter.com, 2014)[18].

\subsection{Types of Bowstring}

There are three main types of bow string that have been used to fit bows. The three types are described as simple, reverse-twisted, or looped. Simple bow strings can be made of any type of fiber material (Archery World, 2016)[19]. These strings are an upgrade from simple strings as they are much stronger for their weight and can be drawn to a higher tension (Biwabursak Online Store, 2015)[20]. Looped strings are the type of string that all modern compound bows use. These are made of one or more loops of material (60 X-Custom Strings, 2018)[21].

\subsection{Target Archery}

Target archery is the most popular form of archery in which members shoot at stationary circular targets at varying distances. Many bows, longbows, bare bows, recurves, and compounds that can use (Pngitem.com, 2017)[22]. The World Archery Federation governs modern competitive target archery (abbreviated WA). WA is the International Olympic Committee (IOC) recognized governing body for all of archery and the Olympics.

\subsection{Training the Archery Posture Efficient}

Archery is a wonderful sport, with many different things to focus on. They may obsess over some archers with their arrows and fletching, while others tune their bow, paying attention to even the minute details (when training, archers receive immediate feedback on every shot (Wells, 2020) [23]. IfI archers are looking to improve their shooting and become more accurate and use the following archery tips for accuracy, they will see their overall shots improve in no time (Archery Dude, 2018) [24].

Step I: The new archers are refocusing hard on the target, buying the newest and best gear and trying every brand of arrow possible to relax that bow grip hand.

Step II: An archer is focused on the target intently, making sure his form and stance are just right, and keeping his draw held as he has taught him. He/she lets the arrow go, and the show is off its mark to relax and do not forget to breathe.
Step III: Many archers practice shots from five yards. The reality is to shoot the distance they can currently shoot accurately to improve over time with practice at the right distance.

Step IV: Posture is important to improving the shot of archers, directly affects their aim, the posture that they should have done it? Don't look at them while doing this, be aware of their posture.

Step V: Some archers, especially younger ones, will release their shot and then immediately look to see where they land. Don't move until your shot has landed and until the arrow hoots at the target.

Step VI: Many archers release their shots too quickly. They simply become impatient and do not aim long enough, the target and aim their shot for at least ten seconds, increasing several times in the 10 second rule.

Step VII: Another largely overlooked practice in archery is how your feet are planted, but fewer of them do and set up for a shot, planting their feet first to cause them to overlook their footing to watch.

Step VIII: Of course, it's important to focus on the shot, but it's important to train the body to shoot accurately and that's where muscle memory comes in, the body should move and feel when aiming and shooting that feeling of release.

Step IX: If they are not shooting their correct draw length, their accuracy is going to plummet. Try shooting at this draw length and compare it to their accuracy from how they were shooting before to shoot the proper draw length for them.

Step X: Arrows are not cheap, especially the great ones. Practice with only the best arrows they can afford. Stick with only those six or more of the same arrows to shoot only the same arrows, every time.

Step XI: The foundation of being an excellent archer is always to have the proper form, doesn't mean that you can shoot the thing accurately by being able to actually shoot ten times better than only shoot a draw weight that they can support.

Step XII: Get a magic marker and count six to a dozen arrows consecutively. Shoot those at a comfortable distance, as they normally do with at least their next ten shooting practices to number their arrows.

\subsection{Background of This Research Study}

As mentioned above in the reports on archery, National Sports University, Lampang Campus is an educational institution under the Ministry of Tourism and Sports is the agency that has assigned about the development of archery to excellence by establishing a sports center for archery excellence in the development of athletes to achieve excellence. It comprises three components: physical fitness, mental performance (psychological fitness) and sport skills (Caruso et al., 1990)[24]. Among the most important psychological constructs for 
psychological fitness are self-regulation and coping strategies, positive and negative effects, perceived control, self-efficacy, self-esteem, and optimism (Robson, 2014)[25]. Stronger muscles can mean more powerful muscles that can do bigger jobs, such as lifting heavier weights, or muscles that will work longer before becoming exhausted (endurance) and flexibility (Healthlinkbc.ca, 2016)[26].Performance of a sports trainer, mental performance of athletes, and physical performance of athletes will influence the development of athletes for the excellence of archers (Mayethaisong et al., 2011)[28].

To develop an archer to the top of the competition level, systematic training and practice of the correct skills will be required. Archery, too, is four key elements: archery technique, physical skill, mental skill, and equipment side.The research team was interested in analyzing this archery skill. This will integrate the archery posture that can shoot 10 points. The time schedule that is spent at each stage of archery in order to utilize the data obtained from the study in the development of archery sport for further excellence achievements of efficient archery postures.

\section{Materials and Methods}

\subsection{Research Aims}

1. To analyze effective archery skills of archers for achieving excellence in the average total scores are more than $80 \%$ of their shooting in 10 times.

2. Compare the physical posture of an archer with an arrow between an arrow that received 10 scoring points and an arrow that was less than 10 scoring points.

3. To associate between the performances abilities of the archers in terms of actual and preferred forms with to their evaluation of the archery skill.

\subsection{Sample Size}

The sample size consisted of 31 athletes who have participated in national and international archery competitions. Using the Recurve bow type in 70 meter distance with the purposive sampling random was selected. We voluntarily selected the sample groups to participate in the test.

\section{Protection of Rights and Ethics}

The Ethics Committee on Research on Humans of the National Sports University has reviewed this research Sports University (Number TNSU030/2020) and conducted research oninto archery shooters. Researchers introduced clarity to protect the sample groups and have signed consent to participate in the research.

\subsection{Research Instruments}

The research instruments were collected information including:

\section{The Sports Game Analysis Kit (SGAK) or Dartfish}

The Sports Game Analysis Kit (SGAK) or Dartfish comprises sports analysis software that was analyzed with the laptop computer. Skills Enhancement and Body Exercise: Playing bow and arrow can strengthen archer's physique, especially the strength of arms, waist and legs, chest and back muscles.

\section{Mini DVVideo Camera Camcorder with Tripod}

Using the Video Camera Mini DV Camcorder with Tripod, this Mini DV Camcorder V-Modal Digital Camera Record Full HD 1080P 20FPS 2.8 Inch 270 Degree Flip Screen Video Camera Camcorder 8X Digital Zoom YouTube Vlogging Camera for Archery Beginners record.

\section{Archery Skill Analysis Assessment Form (ASAAF)}

The adaptation of skill theory for the archery sport of Niklas Isaac (2017)[30] was the original skill. Using the 50-Item Archery Skill Analysis Assessment Form (ASAAF), the archers' skills of their ten skills recorded with the research team, namely; Develop Intense Focus and Concentration (DIFC Skill)(Item 1-5), Gain Clarity of Mind (GCM), Flex Archer Patience Muscle (FAPM), Improve Coordination and Balance (ICB), Build Physical Strength and Stability (BPSS), Boost Archer's Distance Judging Abilities (BADJA), Aim Small and Miss Small (ASMS), Meet Like-Minded People (MLMP), Become a Hunter and Harvest Archer's Own Meat (BHHM), and Discipline and Stick-With-It-Ness (DSN) skills. The ASAAF consisted of 10 skills, each skill included 5 items, and the archer skills were observed by the research and assistant research teams. The archer's hobbits and the behaviours of their posture skills in the responses of five options on the responses Always, Often, Sometimes, Seldom, and Never.

\section{Archers Performance Ability (APA)}

Archers Performance Ability (APA) is the relationship between the shooting accuracy of archers and their body movements, it is reported. The results indicate that the accuracy of an archer's performance that is related to the distance that the archer's centre of pressure on the ground moves in the time interval 10 times prior to arrow release. The relationship appears to be significant for sample archers. This suggests that the ability to achieve body stability is more important in discriminating between archers of intermediate to high-level ability than in discriminating between Actual Form (The form of archers that were not trained and practiced by the trainers and the 
31 expert professionals) and preferred form (most archers must train and practice by the 31 expert professionals).

- Recording paper of the Scoring Shooting for the Actual Form

The actual form that showed and reported on the recording paper of the scoring score shooting of 31 archers who were the sample group of this research project shooting 10 times, the maximum score for each time is 10 and the total score is 100 was designed. The Actual Form scoring records were as before trainers did not train or practice with the archers and the 31 expert professionals. The scoring with their experiences and the recorders were marked and the scores were recorded in the recording paper table for each archer.

- Recording Paper of the Scoring Shooting for the Preferred Form

Similarity: Most archers must be trained and practiced by the 31 expert professionals. We checked the assistant researchers the times for their spending arrangement on their shootings indicated that of the efficient archery posture training analysis of archery shooters for the excellence achievements as a 3-step example, namely; Starting, Aiming, and Releasing steps, responsibility.

- Recording Paper of the Scoring Score Shooting for the Actual Form

The Actual Form that is shown and reported in the recording paper of the scoring score of the shooting of 31 archers who were the sample group of this research project that shooting 10 times, the maximum score for each time is 10. The Actual Form scoring records were as before, the trainers did not train and practice the archers and the 31 expert professionals who competed in the Olympic, Asian, and Sea Games.

- $\quad$ Recording paper of the Scoring Score Shooting for the Actual Form

The actual form that showed and reported the recording paper of the scoring and score shooting of 31 archers who were the sample group of this research project that was shooting at 10 times. The actual form scoring records were as they were before: Trainer did not train and practice with the archers and the 31 expert professionals.

- $\quad$ Recording Paper of the Scoring Score Shooting for the Preferred Form
Similarity: Focused on the achievements of archery excellence with their performance after training and practices with which they watched the videotape experienced by world class archery who used to score the total maximum of 600 for shooting times, or there was a competition result with a total score level that performance as low as 600 scores. We must train most of the archers and practices by the 31 expert professionals. We checked as a 3-step example namely; Starting, Aiming, and Releasing steps, responsibility.

\subsection{Research Procedures}

1. Coordinate with the sample agencies.

2. Prepare a set of 2 cameras to record to collect research data.

3. Explain the methods for collecting data and the benefits of the research to the sample.

4. The sample group warmed up.

5. The sample group tested 3 sets of 70-meter return archery with 5 arrows each in an indoor gymnasium.

6. The video of the archery was separated into 2 groups, the video of the archery received 10 points, and the video of the shot scored is compared to less than 10 points.

7. Archers would be trained and tested in archery within the gymnasium and could watch the video many times. Experts guide archers who may not understand the correct archery skills and posture. An expert will present athletes individually. The researcher and research assistant will observe and receive individual archery documentation.

8. After practicing and practicing until the archer is confident, the expert research group, research assistant, and archer will travel to the outdoor archery field of the National Thai Stadium and carry out the steps outlined in the research (Figure 2).

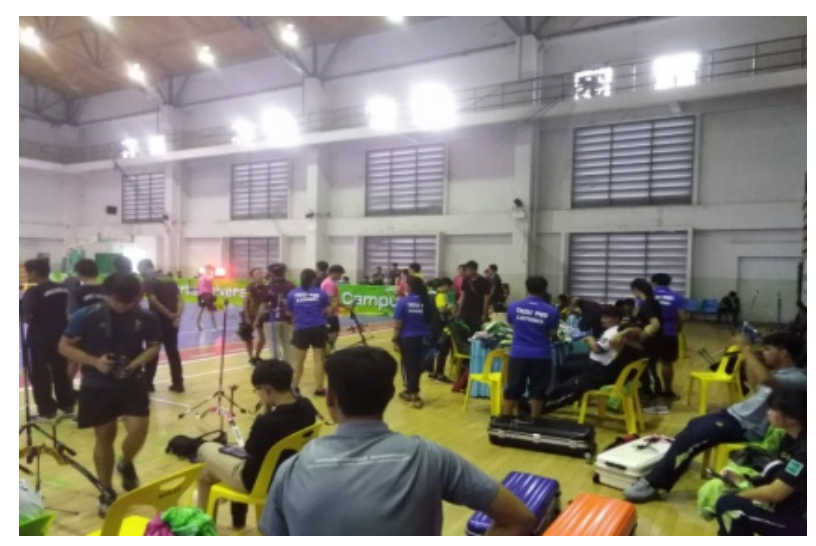

a) Prepare a set of 2 cameras to record for collecting research data 


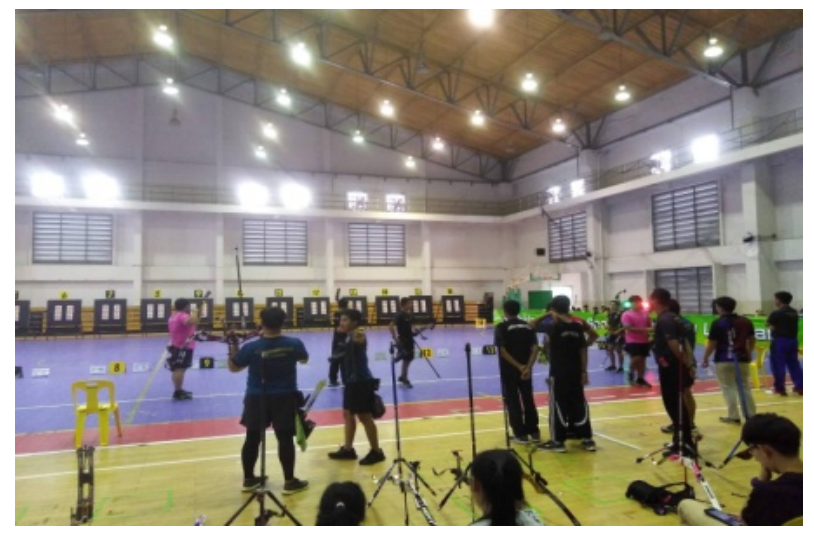

b) The sample group warmed up in the Indoor Gymnasium

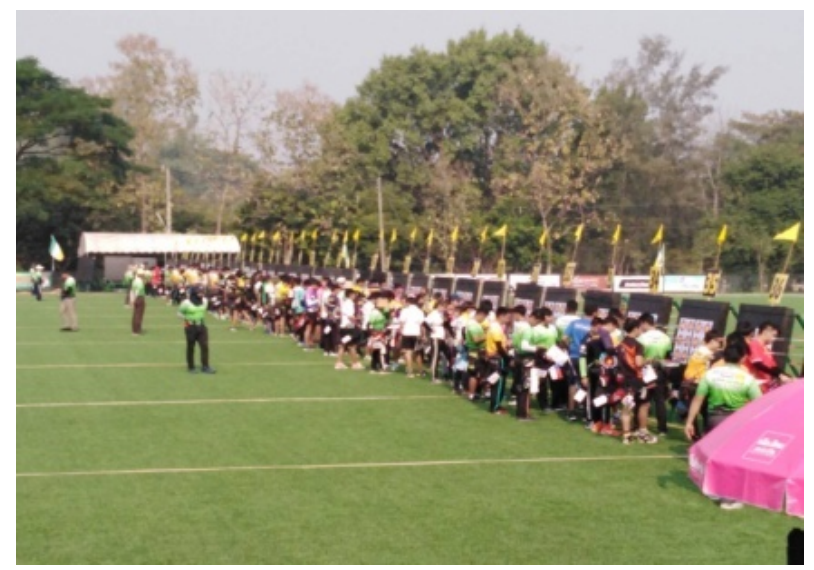

c) The sample group was prepared to shoot for the actual and preferred forms of the sample group in outdoor station

Sources: a), b), and c) Photos by research team (2020)

Figure 2. (a), warmed up in the indoor gym (b), prepared to shoot for the actual and preferred forms of the sample group in outdoor station (c)

9. Experts will check for correct archery skills. The research assistant would prepare to observe the skills of the archer with the questionnaire, and mark archery score record, respectively, the archery numbered 10 arrows.

10. Researchers and research assistants gather information and proceed to the next step of analysis.

\subsection{Data Analysis}

Statistically significant statistics such as mean, standard deviation, variance, F-test, t-test, Cronbach Alpha reliability coefficient, simple and multiple correlations, standardized multiple regression and efficient predictive value of determination were associated (Santiboon 2011) [31].

\section{Results}

\subsection{General Data of the Sample Size}

Variables with measurement levels in nominal scale, such as the value of a variable that is just segmentation or cannot sort differences. Therefore, the variable the report would be reported with means, standard deviation, and variance to provide sufficient statistical power that the reports in Table 1.

Table 1. General data on age, weight, height, and number of times participating in international competitions (NTPIC) for archers

\begin{tabular}{|c|c|c|c|}
\hline General data & Mean $(\overline{\mathrm{X}})$ & $\begin{array}{c}\text { Standard } \\
\text { deviation }(\boldsymbol{\sigma})\end{array}$ & Variance $\left(\boldsymbol{\sigma}^{2}\right)$ \\
\hline Age (year) & $\mathbf{2 3 . 4 7}$ & $\mathbf{7 . 5 0}$ & 56.25 \\
\hline Weight (Kg.) & $\mathbf{6 4 . 4 7}$ & $\mathbf{1 0 . 6 0}$ & 112.36 \\
\hline Height (cm.) & $\mathbf{1 7 1 . 5 0}$ & $\mathbf{4 . 2 7}$ & 18.23 \\
\hline $\begin{array}{c}\text { NTPIC } \\
\text { (Times) }\end{array}$ & $\mathbf{6 . 2 0}$ & $\mathbf{3 . 7 6}$ & 14.14 \\
\hline
\end{tabular}

$\mathrm{N}=31$

The general data of the archers who were the volunteers for the sample size with the average age 23.47 years, weight $64.47 \mathrm{~kg}$, height $171.50 \mathrm{~cm}$, and number of times participating in international competitions (NTPIC) 6.20 times for the archers reported in Table 1.

\subsection{Validity of the Research Instrument for the ASAAF}

The results given in Tables 2, 3, and 4 show that on average the items mean for each of the five ASAAF skills that they contain five items, so that the minimum and maximum scores possible on each of these skills are 5 and 25 , respectively. We calculated the mean of the average item for each skill so that there is a fair basis for comparison between unique skills (Santiboon, 2012) [32].

\subsubsection{Internal consistency (Cronbach alpha) Reliability}

As reported in Table 2, Cronbach alpha reliability coefficient on the ten scales of the AFAF ranges from 0.67 (Improve Coordination and Balance Skill) to 0.88 (Meet Like-Minded People Skill). We expressed the standard deviation in the same units as the original values for the item meaning scores, which ranged from 1.97 to 3.66. We express variance in much larger units, although the units of variance are harder to understand; variance is important in statistical tests and ranges from 3.87 to 13.38 . 
Table 2. Cronbach alpha coefficient, mean, standard deviation, variation, and F-test for the ASAAF

\begin{tabular}{|c|c|c|c|c|c|c|c|}
\hline Skill & a-reliability & $\begin{array}{c}\text { Skill mean } \\
\text { (Total = 25) }\end{array}$ & Item S.D. & Item variance & Average mean $(\bar{X})$ & Standard deviation & F-test \\
\hline DIFC & 0.69 & 19.55 & 2.61 & 6.85 & 3.91 & 0.89 & $3.75^{*}$ \\
\hline GCM & 0.68 & 19.03 & 2.44 & 5.96 & 3.81 & 0.86 & $4.16^{*}$ \\
\hline FAPM & 0.72 & 19.00 & 2.89 & 8.33 & 3.80 & 0.86 & $6.99^{* *}$ \\
\hline ICB & 0.67 & 18.81 & 2.88 & 8.29 & 3.76 & 0.87 & $6.13^{* *}$ \\
\hline BPSS & 0.70 & 19.58 & 3.01 & 9.05 & 3.92 & 0.88 & $6.89^{* *}$ \\
\hline BADJA & 0.74 & 18.77 & 3.66 & 13.38 & 3.76 & 1.05 & $3.56^{*}$ \\
\hline ASMS & 0.71 & 16.42 & 2.81 & 7.92 & 3.28 & 0.83 & 2.23 \\
\hline MLMP & 0.88 & 16.45 & 3.58 & 12.79 & 3.29 & 0.87 & $5.86^{* *}$ \\
\hline BHHM & 0.73 & 21.00 & 1.97 & 3.87 & 4.20 & 0.71 & $19.26^{* * *}$ \\
\hline DSN & 0.70 & 21.68 & 2.44 & 5.96 & 4.34 & 0.71 & $4.44^{* *}$ \\
\hline
\end{tabular}

$\mathrm{N}=31, \mathrm{p}^{*}<.05,{ }^{* *} \mathrm{p}<.01,{ }^{* * *} \mathrm{p}<.001$

Table 3. Cronbach Reliability, Mean, Standard Deviation, Variance, and F-test for the Actual and Preferred APA Ability Forms

\begin{tabular}{|c|c|c|c|c|c|}
\hline Ability Form & $\boldsymbol{\alpha}$-Reliability & Mean & Standard deviation & Variance & F-test \\
\hline Actual form & 0.56 & 78.97 & 6.04 & 36.50 & $4.93^{* * *}$ \\
\hline Preferred form & 0.66 & 85.61 & 5.26 & 27.65 & $3.70^{* * *}$ \\
\hline
\end{tabular}

$\mathrm{N}=31,{ }^{*} \mathrm{p}<.05, * * \mathrm{p}<.01, * * * \mathrm{p}<.001$

The average mean scores on ten skills range from 3.28 (Aim Small and Miss Small Skill) to 4.34 (Discipline and Stick-With-It-Ness Skill). Standard deviation of the scale means ranged from 0.71 to 1.05 . An F-test is any statistical test in which the test statistic has an F-distribution under the null hypothesis. It is most often used when comparing statistical models that have fitted to a data set and the predicted variables ranged from 2.23 to $19.26^{* * *}$.

\subsubsection{Validity of the APA}

Using statistically significant with the Cronbach alpha coefficient and the mean correlation, the sample received from the sample in this present study as indices of reliability, variance and $\mathrm{F}$ test for the actual and preferred APA ability forms of the archers as reported in Table 3.

As reported in Table 3, statistically significant for the archers shooting performance abilities of their before, watching the archery videos, training and practicing by the trainers (Actual From), and after watching the archery videos, training and practicing by the trainers (Preferred Form) with analysis on Cronbach alpha reliability, mean, $\mathrm{SD}$, variance, and $\mathrm{F}$ test for the Actual Form $(\alpha=0.56$, means $=78.97$, S.D. $=6.08$, Variance $=36.50$ and $\mathrm{F}$ test $=$ 4.93, significantly). In terms of the Preferred Form, $\alpha=$ 0.66 , means $=85.61$, S.D. $=5.26$, Variance $=27.65$ and $\mathrm{F}$ test $=3.70$, significantly, respectively.

\subsection{Comparisons between Archers' Responses to Their Scoring Performances for Actual and Preferred Forms}

Table 4 shows the responses of the archers to their scoring performances for the actual and preferred forms. Bows and arrows have been important tools for hunting, warfare, and sport. Drawback, aim, and release, watch the archer arrow fly and smack the target with a satisfying thud. From skills that improve their mind-body connection. Using the t-test analysis, correlations with paired samples were tested.

Table 4. Comparisons between archers' responses of their scoring performances for the actual and preferred forms

\begin{tabular}{|c|c|c|c|c|}
\hline Skill & $\begin{array}{c}\text { Mean } \\
(\bar{X})\end{array}$ & $\begin{array}{c}\text { Standard } \\
\text { deviation }\end{array}$ & t-test & Significant \\
\hline $\begin{array}{c}\text { Preferred } \\
\text { Form }\end{array}$ & 85.613 & 5.259 & \multirow{2}{*}{$5.542^{* * *}$} & .000 \\
\cline { 1 - 3 } $\begin{array}{c}\text { Actual } \\
\text { Form }\end{array}$ & 78.958 & 6.042 & & \\
\hline
\end{tabular}

$\mathrm{N}=31,{ }^{*} \mathrm{p}<.05,{ }^{* *} \mathrm{p}<.01,{ }^{* * *} \mathrm{p}<.001$

The results in Table 4 as reported the comparing means of the archers' responses to their scoring performances for the actual form (who have never trained and practiced through archery sport videos and by trainers) and preferred forms (who have trained and practiced through archery sport videos and by trainers). We differentiated statistically significant at the level of 0.01 , differently. 


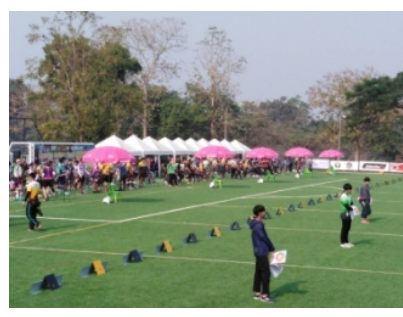

a) Recorders

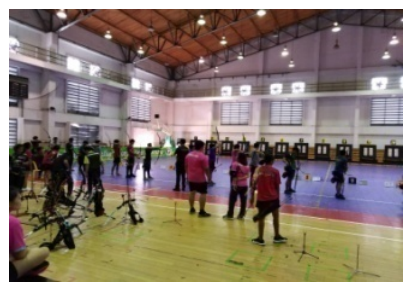

e) Training before in indoor stadium

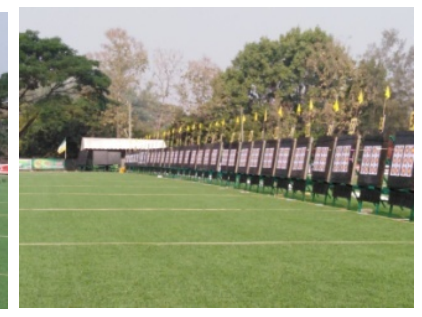

b) Targets

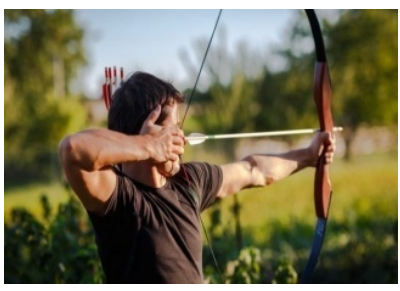

f) starting posture training

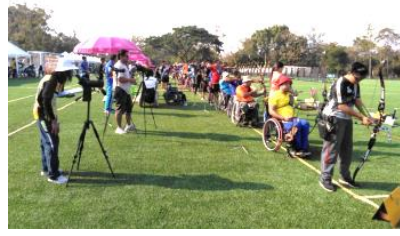

c) Archers' preparing

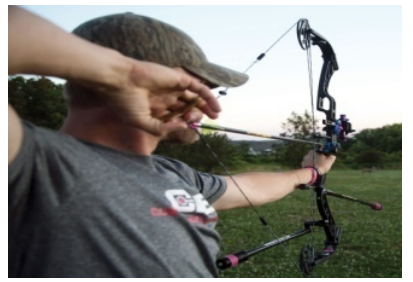

g) Aiming posture training

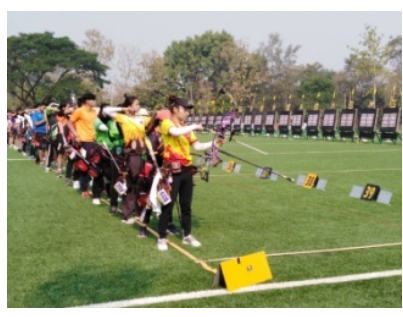

d) Archers' beginning

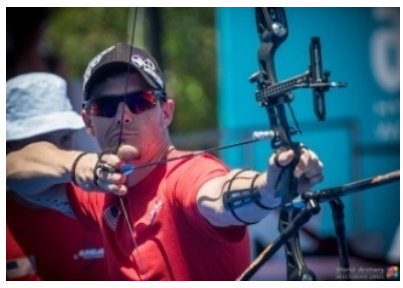

h) Releasing posture training

Sources: a), b), c), d), and e) Photos by research team; f), g), and h) (Einsmann, 2017)[34]

Figure 3. Creative analysis of efficient archery posture training analysis

\subsection{Analysis of Archery Skills}

A good of archery skill: Bows and arrows have been important tools for hunting, warfare, and sport that extend far beyond the target was reported of analysis of archery skills (Figure 3 ).

Analysis of archery skills, it consists of 10 skills of standing (the Stance), the skill of the bow (Hooking), the draw (Drawing), the under the chin (Anchoring), the skill to transfer the weight while drawing still (Loading/Transfer to Holding), the skill to build physical strength and stability, Develop intense focus and concentration skill, Aiming skill (the position of the bow through the bow or aiming center), the arrow release skill (Release), maintaining the shooting position (Follow through). We summarize of the 10 posture-standardized skills as summarized as below.

1. The Stance: The open stance of controlling the weight falls on the front foot slightly more than the balance.

2. Hooking: The thumb and little finger are relaxed, not tense. The back of the hand and wrist are straight, not bent. The back of the hand that is connected to the string that is tilted slightly away from the bow.

3. Drawing: The position of the hand that holds the bow is the palm area at the base of the thumb, the side arm that holds the bow forearms facing out sideways, parallel to the ground. The arms are straight, not bent over. The shoulder lock does not follow the arm while moving.
4. Anchoring: Positions of the index finger under the chin close to the chin. The thumb naturally released under the chin, next to the neck with the elbow on the bow line, is slightly higher than the line of the arrow; not bent elbow is in the same line.

5. Loading/Transfer to Holding: Shifting a strong weight while still, when drawing the bow to the point under the chin using the muscles of the forearm, forearm, and hand. When the line is still, all focus is directed towards the dorsal scapula.

6. Physical strength and stability: Improveing hand-eye coordination. The primary benefit of archery. We use all body component when practicing, especially arms, hands, chest, and shoulders.

7. Develop intense focus and concentration: Increasing the strength of archer focus gradually. Create a distraction-to-do list. Practice mindfulness throughout the day

8. Aiming: Aim through the bow window with an average of 4.60 seconds between aiming and release.

9. Release: Support fingers along, the string is released by loosening the fingers on the string. After the arrow is released, the height of the right elbow is level with the shoulder blades.

10. Follow through: The left arm remains in the same line as when drawing the line, and the right arm condition after release the arrow 
Table 5. Associations between Archers' Excellence Achievements for the ASAAF and their Actual APA in terms of simple correlation (r), multiple correlations (R) and Standardized Regression Coefficient $(\beta)$

\begin{tabular}{|c|c|c|c|c|c|c|}
\hline Variables & $\frac{\text { Mean }}{(\bar{X})}$ & S.D. & $\begin{array}{c}\text { Simple } \\
\text { Correlation (r) }\end{array}$ & $\begin{array}{c}\text { Standardized } \\
\text { Regression Validity } \\
(\beta)\end{array}$ & $\begin{array}{c}\text { Multiple } \\
\text { Correlation (R) }\end{array}$ & $\begin{array}{l}\text { Efficiency } \\
\text { Predictive } \\
\text { Value }\left(\mathbf{R}^{2}\right) \\
\end{array}$ \\
\hline ASAFF (250) & 190.29 & 13.05 & \multirow[b]{2}{*}{$0.3753^{* * *}$} & \multirow[b]{2}{*}{$0.2431 * *$} & \multirow[b]{2}{*}{$0.7142 * *$} & \multirow[b]{2}{*}{$0.5102 * *$} \\
\hline $\begin{array}{c}\text { Actual APA Form } \\
(100)\end{array}$ & 78.97 & 6.04 & & & & \\
\hline
\end{tabular}

$\mathrm{N}=31, * \rho<0.05, * * \rho<0.01, * * * \rho<0.001$

Table 6. Associations between Archers' Excellence Achievements for the ASAAF and their preferred APA in terms of Simple Correlation (r), Multiple Correlations (R) and Standardized Regression Coefficient $(\beta)$

\begin{tabular}{|c|c|c|c|c|c|c|}
\hline Variables & $\begin{array}{l}\text { Mean } \\
(\bar{X})\end{array}$ & S.D. & $\begin{array}{c}\text { Simple } \\
\text { Correlation (r) }\end{array}$ & $\begin{array}{c}\text { Standardized } \\
\text { Regression Validity } \\
(\beta) \\
\end{array}$ & $\begin{array}{c}\text { Multiple } \\
\text { Correlation (R) }\end{array}$ & $\begin{array}{l}\text { Efficiency } \\
\text { Predictive } \\
\text { Value }\left(\mathbf{R}^{2}\right) \\
\end{array}$ \\
\hline ASAAF (250) & 190.29 & 13.05 & \multirow[b]{2}{*}{$0.4127^{* * *}$} & \multirow[b]{2}{*}{$0.2879 * *$} & \multirow[b]{2}{*}{$0.8279 * *$} & \multirow[b]{2}{*}{$0.6854^{* *}$} \\
\hline $\begin{array}{l}\text { Preferred APA } \\
\text { Form (100) }\end{array}$ & 85.61 & 5.26 & & & & \\
\hline
\end{tabular}

$\mathrm{N}=31, * \rho<0.05, * * \rho<0.01, * * * \rho<0.001$

\subsection{Associations between Archery Skill Analysis Assessment Form (ASAAF) and Archers Performances of Their Actual and Preferred Forms for the APA of Their Efficient Archery Posture Training Analysis To Archery Shooters For Excellence Achievements}

Using two variables of Archery Skill Analysis Assessment Form (ASAAF) scales that were independent variable and Archers Performances of their Actual and Preferred Forms for the APA (dependent variable) that have only two variables, the standardized slope (beta) is formally equivalent to Pearson's ( $r$, and $R$ ) of two variables the relationship was assessed that reported as Tables 5 and 6.

Simple correlation is a measure used to determine the strength and the direction of the relationship between two variables, ASAFF and Actual APA. A simple correlation coefficient can range from -1 to 1 . However, maximum (or minimum) values of some simple correlations cannot reach unity (i.e., 1 or -1 ). In Table 5 reports of the simple correlation is positive value and indicates of $0.38(p<.001)$, significantly.

Simple linear regression $(\beta)$ is a model that describes the relationship between one dependent and one independent variable, the $\beta$ value indicates that of 0.24 $(p<.01)$, significantly.

Multiple correlation (R) is an extension of linear correlation that permits researchers to correlate a set of independent (or predictor) variables with a single dependent (or criterion) variable. The $\mathrm{R}$ value indicates that of $0.71(p<.01)$, significantly.

$\mathrm{R}$-squared is a goodness-of-fit measure for linear regression models. This statistic indicates the percentage of the variance in the dependent variable that the independent variables explain collectively. After fitting a linear regression model, you need to determine how well the model fits the data. In finance, an R-Squared above 0.7 would generally be seen as showing a high level of correlation, whereas a measure below 0.4 would show a low correlation. An $\mathrm{R}^{2}$ of 1.0 indicates that the data perfectly fit the linear model. Any $\mathrm{R}^{2}$ value less than 1.0 indicates that at least some variability in the data cannot be accounted for by the model (e.g., an $\mathrm{R}^{2}$ of 0.5 indicates that $50 \%$ of the variability in the outcome data cannot be explained by the model).

The results of this research study, the $R^{2}$ value indicates that $51.02 \%$ of the variance of the skills of the archer according to their actual performance abilities was relatively attributable.

In table 6, as reported of associations between archers' excellence achievements for the ASAAF and their preferred APA in terms of Simple Correlation (r), Multiple Correlations (R) and Standardized Regression Coefficient $(\beta)$, and the coefficient predictive value determination $\left(R^{2}\right)$ were assessed.

In Table 6, associations between the analysis of archery skills for ASAAF and the performance of archers in their preferred form for the APA to their efficient analysis of archery posture training we found in archery shooters for the excellence achievements the $\mathrm{r}, \beta$, and $\mathrm{R}$ are significant.

Table 6 reports associations between the analysis of archery skills for ASAAF and the performance of archers in their preferred form for the APA to their efficient analysis of archery posture training we found in archery shooters for the excellence achievements the $\mathrm{r}, \beta$, and $\mathrm{R}$ are significant.

The $R^{2}$ value indicates that $69 \%$ of the variance in the analysis of archery skills according to their actual performance abilities was attributable to an efficient analysis of archery posture training of archery shooters for the excellence achievements after they were trained and practiced by the design of the research, significantly. 


\section{Discussions}

Archery in Thailand began on September 12, 1969, when Her Royal Highness Princess Maha Chakri Sirindhorn visited the Department of Territorial Protection and made an arrow. This has created widespread interest in archery. In 1977, 1977, the archery was the first year that was included in the 9th SEA Games in Malaysia and the 8th Asian Games in 1978 in Thailand. The archers of Thailand have participated in four SEA Games, one World Archery Sport, and the Annual Asian Grand Archery Competition until now 2011 (33 times), and have never appeared to win any awards and awards were never qualified as an athlete to compete in the Olympics even once.

Analysis results of archery posture of Thai national archers in 10 items includ: stances, hooking, drawing, anchoring, loading/transfer to holding, physical strength and stability, develop intense focus and concentration, aiming, and following postures, the information that corresponds to the archery posture of world-class archers. For example: The Stance is the placement and control of the lower half of the body, from the hips down. Once the posture is achieved, the same posture is used throughout the Shot Cycle, except for the coiling that occurs when lifting the bow.

The Thailand National Sports Universities are the public higher education institution under the Ministry of Tourism and Sports Formerly known as the Institute of Physical Education, it produces teachers, especially physical education and health education teachers after the organization changes to be a great university according to the National University of Sports Act 2019. At the current time, there is an increasing role in the production of professional personnel, sports science, and increased health. The National Sports University consists of 17 campuses and 13 sports schools spread throughout Thailand. The National Sports Universities, Lampang Campus is on the Northern, Northern and Mahasarakham Campus is in a Northeastern Region that produces sports graduates, including physical education teachers, health education, sports scientists, sports coaches, and recreational practitioners and sports journalists.

The failure of archery in Thailand, a key factor in the failure of archery, is the much better development of other countries' sports. Essential elements of Thai athletes did not reach their target, namely the abilities of Thai athletes, combined with the abilities of competing nations. This situation is the main important for this research study to investigate and solve the problems for archery sport in Thailand. However, today, the world is taking sport very seriously, as it has become part of people's lifestyles. It also plays a role in economic and social development. As long as the world trend has changed and entered various competitions. Seriously, sports are therefore an option or an activity that the entire nation cannot overlook
(Boonyanuwat, 2016) [35]. Sports in Thailand, today the trend for sports is on the rise and it is receiving a lot of attention. This is because sports are part of creating and giving happiness to members of society and their families. Especially when athletes create results that bring victory and reputation to the nation. The people of Thai society are completely happy. Meanwhile, today sport is one business that governments and entrepreneurs are promoting, leading to a drive to further develop the economy and society according to government policies.

\section{Conclusions and Suggestions}

Creative quantitative research methods were used to analyze the skills and abilities of the archers with the experts who can train and practice with themselves and use the excellence achievements of innovative instructional archers by Augmented Reality Technology (AR) classes in outdoor and indoor environments with the 31 athletes who have participated in national and international archery competitions as a sample size. The recurve bow type in 70-meter distance with shooting was selected. The Sports Game Analysis Kit (SGAK) consists of sports analysis software that was analyzed. Video Camera Mini DV Camcorder with tripod, this Mini DV Camcorder V-Motal Digital Camera Recorder was recorded. The adaptation of the skill theory for the archery sport of Niklas Isaac (2017) [30] was the original skills to the 50-Item Archery the archers evaluated the skill analysis assessment on 10 skills. The Archers Performance Ability (APA) was when we reported the relationship between the shooting accuracy of archers and their body movements with the actual and preferred skills forms (APA) on 10 times were observed.

Most archers have an average age of 23 years, weight of $64 \mathrm{~kg}$, a height of $172 \mathrm{~cm}$, and a number of times that they have participated in international competitions. Statistically significant with the scale mean, item mean, standard deviation, variance, and F-test analysis were predicted significantly. Comparisons between Archers' responses to their scoring performances for the actual and preferred forms were differentiated significantly at the level of.001. Average mean scores of the actual as 79 and 86 for the actual and preferred forms of their excellence achievements were achieved.

Analysis of archery skills, it consists of 10 skills of standing (the Stance), the skill of the bow (Hooking), the draw (Drawing), the under the chin (Anchoring), the skill to transfer the weight while drawing still (Loading/Transfer to Holding), the skill to build physical strength and stability, Develop intense focus and concentration skill, Aiming skill (the position of the bow through the bow or aiming center), the arrow release skill (Release), maintaining the shooting position (Follow through). 
Associations between Archery Skill Analysis Assessment Form (ASAAF) and Archer Performance Abilities of their Actual and Preferred Forms for the APA of their efficient archery posture training analysis for archery shooters for excellence achievements were evaluated. The R2 values indicate that $69 \%$ of the variances in archers' abilities to their archery performance skills were attributable to their actual and preferred analysis of efficient archery posture training analysis of archery shooters for the excellence achievements, differently.

\section{REFERENCES}

[1] Paterson W. F., “Archery,” Encyclopedia of Archery, pp. 97-103, 1985.

[2] Lombard M., "The tip cross sectional areas of poisoned bone arrowheads from southern africa," Journal of Archaeological Science, vol. 33, no. 1, 2020. DOI:10.1016/j.jasrep.2020.102477.

[3] Backwell L., d'Errico F., Wadley L, “Middle stone age bone tools from the Howiesons Port Layers, Sibudu Cave, South Africa," Journal of Archaeological Science, vol. 35, pp.1566-1580, 2008. DOI:10.1016/j.jas.2007.11..006

[4] Duvernay T. A., Duvernay N. Y., "Korean traditional archery,” Handong Global University. 2007.

[5] Zutterman C., "The bow in the ancient near East. A re-evaluation of archery from the late second2nd millennium to the end of the achaemenid empire," Iranica Antiqua, pp. 38119-165. 2013.

[6] Gunn S., “Archery practice in early Tudor England,” Past and Present Journal, vol. 209, no. 1, pp. 53-81, 2010.

[7] Spacewar.com., "Bows and arrows: Deadly weapons of rural Kenya's war,” Njoro, Kenya (AFP), 2012. Retrieved: http://www.spacewar.com/reports/Bows_and_arrows_dead ly_weapons_of_rural_Kenyas_war_999.html

[8] Okeowo A., "Peace and poison arrows in Kenya,” Nairobi, the Zen Pagan, 2012.

[9] Bertalan D., “Traditional, traditional bowyers Encyclopedia: The bow hunting and bow making world of the nation's top crafters ff longbows and recurves,”.Amazon.co.uk, 2007.

[10] World Archery., "Olympic games archery competition description,” Official Bulletin. 1994.

[11] Hunthacts.com., "Best recurve bow reviews 2018 - Top rated for the money,” Hunthacts.com, 2018.

[12] Einsmann S., "Compound bows everything you need to know,” Archery Bow Club, 2020.

[13] Archery Dude., "Should I buy a bow or a crossbow?,' Archery.com. 2020.

[14] Seokgyu-Choi O. G., Jeong H. S., "The disturbance of war: The ancient origin and development of korean archery," The International Journal of the History of Sport, vol. 27, no.
3, pp. 523-536, 2010. DOI:10.1080/09523360903556824. S2CID 161376479

[15] Sontrop P., 'What is crossbow archery? Archershub.com. https://archershub.com/what-is-crossbow-archery/. 2021.

[16] James D., "What is the best beginner bow \& archery style?,” Targetcrazy.com.,2021.

[17] Brockington, M.. “Target: Target archery rounds," calcresult.com, 2017.http://www.calcresult.com/reference/ archery/target_archery_reference.html.

[18] owhunter.com., "Fletching," The Wisconsin Bowhunter Ed Course, 2014.https://www.bowhunter-ed.com/wisconsin/st udyGuide/Fletching/302051_8860/.

[19] Archery World., “Archery recurve bow arrows fiberglass arrow 24/26/28 inch hunting shooting practice target for beginners kids youth sport outdoor' of 12,”. Amerzon.co, 2016.

https://www.amazon.com/Archery-Fiberglass-Shooting-Pr actice-Beginners/dp/B07YJNDWNB. 2016.

[20] Biwabursak Online Store., "Parabolic feathers archery arrow fletching hunting practice equipment 2". Biwabursak.com, 2015. https://www.biwabursak.com/inde x.php?main_page=product_info\&products_id=22659.

[21] 60 X-Custom Strings., "Types of bowstrings: Simple, reverse-twisting and looped,” 2018. https://www.60xcusto mstrings.com/blog/types-of-bowstrings-simple-reversetwis ted-looped/ (accessed Mar. 9, 2018).

[22] Pngitem.com., "Archery set with wizard beginner recurve bow dacron: Simple bowstring for archery," 2017. Retrieved from https://www.pngitem.com/middle/hiwJJm_ archery-set-with-wizard-beginner-recurve-bow-dacron/.

[23] Wells W., "10 training exercises that will make your archery practice more efficient,”' Lausanne, Switzerland, 2020.

https://worldarchery.sport/news/178467/10-training-exerci ses-will-make-your-archery-practice-more-efficient. (accessed August 30, 2020).

[24] Caruso C. M., GillD. L., Dzewaltowski D. A., McElroy M. A," "Psychological and physiological change in competitive success and failure," Journal of Sport and Exercise Psychology, vol. 12, pp. 6-20, 1990. http://libres.uncg.edu/ ir/uncg/f/d_gill_psychological_1990.pdf

[25] Robson S., "Psychological fitness and resilience: A review of relevant constructions, measures, and links to well-being," Spring, vol. 4, no. 1, p. 6, 2014. https://www.ncbi.nlm.nih. gov/pmc/articles/PMC5051974/

[26] Healthlinkbc.ca., “The three kinds of fitness,” 2016. https://www.healthlinkbc.ca/health-topics/ta3112. 2

[27] Mayathaisong S., Pongboriboon Y., Urachai S., Sriampai A., "Development of a causal model to manage excellence in sports among students of sports schools," The 12th KhonKaen UniversityGraduate Research Conference, 2011. https://gsbooks.gs.kku.ac.th/54/grc12/2011.

[28] Isaac N., "10 skills every man can gain from archery'. Guy Skills Men's Blog News. 2017. https://guycounseling.com/ archery-man-skills/. 2017. (accessed June 4, 2017).

[29] Santiboon T., "My school and my dream school climate," Proceeding at the 4th International Conference on 
Educational Reform 2011 (ICER 2011) 'Equity in Education’. Luang Prabang. Lao People's Democratic Republic, 2011.

[30] Santiboon, T., “Assessing science students’ perceptions in learning activities achievements in physics laboratory classrooms at Udon Thani Rajabhat University,” The 2012 International Conference on Education and Management Innovation IPEDR, vol.30, 2012, IACSIT Press, Singapore.

[31] Santiboon, T., "School environment inventory in primary education in Thailand'. Merit Research Journal and Review. Vol. 1, no. 7, pp. $34-41,2013$.

[32] Einsmann S., "Ask the pros: Which exercises strengthen archery muscles? Archery360.com, 2017. Retrieved : https://archery360.com/2017/05/15/ask-pros-exercises-stre ngthen-archery-muscles/. 2017. (accessed May 15, 2017).

[33] Boonyanuway, R., "Sports and added value economic and social,” Matichon Online, 2016. https://www.matichon.co.t h/columnists/news_287377 2016. 